May 2021

\title{
What's Mine Is Yours: The History of U.S. Tool-Lending Libraries
}

Samantha Hamilton

San José State University, samantha.hamilton@sjsu.edu

Follow this and additional works at: https://scholarworks.sjsu.edu/ischoolsrj

Part of the Library and Information Science Commons, and the United States History Commons Acknowledgements

This article is adapted from a term paper written for Professor Donald Westbrook's Applied Research Methods course. Many thanks to Professor Westbrook for his sage advice and consistent encouragement throughout the research process. I also want to express my appreciation for the time and effort put in by Kyle Stokely to look over this work.

\section{Recommended Citation}

Hamilton, S. (2021). What's Mine Is Yours: The History of U.S. Tool-Lending Libraries. School of Information Student Research Journal, 11(1). https://doi.org/10.31979/2575-2499.110104 Retrieved from https://scholarworks.sjsu.edu/ischoolsrj/vol11/iss1/4

This article is brought to you by the open access Journals at SJSU ScholarWorks. It has been accepted for inclusion in School of Information Student Research Journal by an authorized administrator of SJSU ScholarWorks. For more information, please contact scholarworks@sjsu.edu. 


\title{
What's Mine Is Yours: The History of U.S. Tool-Lending Libraries
}

\begin{abstract}
Tool lending is a relatively new phenomenon in the world of libraries. Instead of loaning books, libraries with tool collections lend kitchen and yard tools to ambitious do-it-yourselfers. These tools can be used to tackle home projects or do seasonal cleanup without burdening borrowers with concerns about cost or storage. As these libraries gain popularity and begin to expand in the U.S., it is worth taking a look at their origins. As it is presented in the current literature, tool libraries began in 1979 with the founding of the Berkeley Tool-Lending Library (BTLL). Information unearthed from newspaper clippings, blog posts, and websites, however, support the existence of a much earlier tool library in Grosse Pointe, Michigan. Based on this finding, the paper will present a revised timeline that puts the birth of tool libraries in the 1940s. In doing so, the paper will correct the existing narrative of these unique libraries and firmly establish Grosse Pointe Library-not the BTLL-as the first of its kind.
\end{abstract}

\section{Keywords}

tool libraries, object-lending libraries, library history, United States

\section{Acknowledgements}

This article is adapted from a term paper written for Professor Donald Westbrook's Applied Research Methods course. Many thanks to Professor Westbrook for his sage advice and consistent encouragement throughout the research process. I also want to express my appreciation for the time and effort put in by Kyle Stokely to look over this work.

\section{About Author}

Samantha Hamilton (she/her) is a San José State University alumna who graduated with her master's in library and information science (MLIS) in May 2021. She is currently a graduate student at Johns Hopkins University, where she is studying environmental sciences and policy to further her aspirations of becoming an environmental librarian/archivist. Her research interests include sustainable professional practices in information settings as well as the history of sustainable library initiatives like tool lending. Outside of the classroom, Samantha enjoys engaging in species conservation efforts and birdwatching in her hometown of Las Vegas. 
In the middle of their latest project, an amateur woodworker runs into a snag. They double-check their toolbox and fish through the shed, but no amount of digging turns up the piece of equipment they need most: the bow saw. The frustrated woodworker considers purchasing the equipment at a hardware store, but on second thought, they wisely opt to borrow it from the West Seattle Tool Library. There, they can lease a saw without needing to spend a dime or worry about storing it after use.

More than fifty U.S. tool-lending libraries like the West Seattle Tool Library in Washington are in operation today, but they were not always so numerous. Where and when, one might ask, did the practice of tool lending in libraries begin? Just decades ago, they were nebulous ideas in librarians' minds that lacked the necessary support to get off the ground. It was not until the late 1970s, as most historians see it, that the first tool library in the country materialized. The Berkeley Tool Lending Library (BTLL) in California was formed as an extension of the community's public library in 1979. It was originally housed in a portable trailer, staffed by a single employee, and had 500 tools for lending (Berkeley Public Library, n.d.). Its disorganized beginnings made the BTLL seem like a novel idea, leading many to assume that it was the first creation of its kind. The BTLL, though, was not the innovative pioneer historians have made it out to be. In fact, the BTLL belongs to a second generation of American tool libraries that stands on the shoulders of forgotten predecessors. Decades before the emergence of the BTLL, little-known tool libraries were quietly transforming the traditional library model.

To give these unsung institutions the recognition they deserve, the history of tool-lending libraries must be rewritten. Rather than beginning with the BTLL, the timeline must extend further into the past and start with the actual first U.S. tool library: the Grosse Pointe Library. Other libraries that came before the BTLL will also be explored to make clear that the BTLL owes its existence to several forerunners. Instead of being the path-breaking institution historians have cast it as, Berkeley's library must be re-characterized as the successor of trailblazing tool libraries in Michigan, Ohio, and Washington. After presenting the revised historical timeline, it will be evident that the BTLL could not have started from scratch; it merely added to the progress made by others.

\section{Literature Review}

Before delving into the updated history of American tool libraries, it is essential to examine the groundwork laid by scholars. Literature on tool libraries is scant, with little research having been conducted on these institutions. What few scholarly works have been written about them will be couched in a broader literature review on object-lending libraries. Though these libraries, too, garner minimal attention, they are worth probing to better understand libraries that loan unconventional items. From this literature review, it should be apparent that this area of library science has been largely neglected and requires fresh research to fill its missing pieces. In particular, gaps related to the origin of U.S. tool libraries will surface in this section and be addressed in the discussion.

\section{Object-Lending Libraries}


In the past half-century, libraries in the U.S. have shown themselves to be more than just book repositories. New community demands have put pressure on them to abandon their reputation as sterile warehouses and create a new brand. Especially with the advent of the Internet, fewer and fewer individuals have been visiting libraries to borrow their texts (Martell, 2008). Instead, people are using phones to get information and looking to libraries to solve other pressing problems (Dahlkild, 2011). In response, libraries have built unique collections that have new "value and usefulness" for their patrons (Söderholm, 2018, p. i). These collections, however, are not made up of print works as one may expect; they are comprised of art, toys, plant seeds, and other objects not typically associated with libraries. Unusual as they may seem, these bookless libraries are fulfilling the material and even social needs of their local communities (Söderholm, 2018).

In spite of the novelty of object-lending libraries, Söderholm contends that they are a natural progression from what has already existed. He points out that games and music - two unlikely categories of library objects - have been part of collections since the second half of the twentieth century (Söderholm, 2018). These items, much like tools, do not readily conform to the usual materials offered by libraries but were incorporated to meet patrons' recreational needs. Riley (2014) also argues that object-lending libraries are a logical next step given the rising popularity of bookless libraries. With more books making the transition from print to pixels, people are getting used to the idea of shrinking in-house collections and expanding digital libraries (Moyer \& Thiele, 2012; Riley, 2014). If patrons are becoming acclimated to borrowing non-physical items, surely they can get used to checking out baking pans, musical instruments, and other atypical materials. Both Söderholm and Riley believe that libraries are primed to make the small jump from books to objects and that patrons, too, are ready for objectlending libraries.

Though some have raised concerns about libraries' pivot from lending publications, even suggesting that they may be on the verge of an identity crisis, libraries are eager to embrace something new (Svensson, 2018). Individuals worried that libraries are straying too far from their roots should be comforted by the fact that these institutions are still sticking to their same function (community lending) but simply expanding their pool of materials. It is true that the shift from loaning books to objects may require adjustment for librarians and patrons, possibly forcing them to divorce their association of libraries with texts (Scott, 2011). However, libraries are just doing the same thing in a different way. Had libraries stuck to their original model as hoped for by Svensson, they would risk facing obsolescence in the modern world.

\section{Tool Libraries}

Despite the promising future of tool and other object-lending libraries, the scholarly literature on these institutions is surprisingly underdeveloped. What little research has already gone into the subject focuses mostly on tool libraries that are yet to exist. Take, for instance, Worthington Library's published article on future trends. In 2010, library staff predicted that they would build a bikelending program and tool-circulating collection in the coming years (Staff of the 
Worthington Library, 2010). More than a decade later, neither idea has come to fruition, and the tool collection that was to be has been put on hold indefinitely. Sadly, the Worthington Library is not alone in populating the literature with dreamed-up tool libraries. Others like Söderholm and Nolin (2015) envision public libraries reworking their community roles and physical spaces to become tool libraries by the dozens. Having come to terms with their limitations in the digital age, libraries will re-evaluate their in-house collections and lean on tool distribution to stay relevant (Söderholm \& Nolin, 2015). Six years out from their predictions, tool collections have increased in number but failed to take off as Söderholm and Nolin had anticipated. Their work, in conjunction with Worthington Library's, captures the current status of the literature well. Rather than abounding with research on existing tool libraries, it is clogged with papers focused on imagined ones that never caught on.

Other scholars contribute to these limited talks by providing generic blueprints that library staff can follow to build their own tool collections. In fact, many of these publications frame tool collections as mere extensions of public libraries and discuss how librarians can develop them from scratch. Gunnels and Green's (2018) analysis fits this mold perfectly as it guides readers through the process of forming a tool collection. Their work focuses mainly on the logistics including initial funds, long-term costs, storage, and upkeep. Gunnels and Green (2018) also recommend tapping into the power of social media or distributing a survey to identify potential users before creating a tool collection. Hult and Bradley's (2017) article adds to this conversation by exploring a case study of a Swedish tool collection in the city of Malmö. Paying particular attention to the materials and methods that went into the collection's construction, Hult and Bradley (2017) discover that one of the best ways to establish a tool collection is by garnering support from local officials. Though this Swedish collection is miles away from the U.S., Hult and Bradley's study was done with the hopes of encouraging others to develop their own tool-lending platforms. Their paper also defends the legitimacy of tool collections by discussing their institutional belonging in public libraries (Hult \& Bradley, 2017).

In other works that make up the meager tool library literature, scholars have mentioned in passing the history of these institutions. A consensus among researchers exists that Berkeley was ground zero for tool lending in U.S. libraries. One author has even gone so far as to applaud BTLL for its successful "experiment," which has supposedly had an "outsized...impact on national and international culture" (Broner, 2017, p. 30). In further praise of Berkeley, journalist Dave Weinstein (2008) asserts that the town is responsible for many "firsts," including a tool-lending library (p. 12). The idea that the BTLL was the first of its kind has even moved beyond academia and into the general public. Magazines are adopting this account and naming the BTLL as the "first of such services" ("Lending tools for the hands as well as the mind," 2011). Many publications are pointing to the BTLL as the founder of the tool library movement, but this assumption is seriously flawed. The current narrative leaves out a handful of libraries that were established well before BTLL, including the first true tool library in Grosse Pointe, hence the need to revise the current 
timeline.

\section{Discussion}

The following section aims to reinvent the existing narrative on tool libraries by stitching together news clippings, refereed articles, blog posts, and websites. The revised history will be segmented into three generations that collectively span the time from tool libraries' inception to present day. Each emerged from a special set of circumstances, struggled with distinctive challenges, and made unique contributions to the library world. By studying them together, it is hoped that one can grasp the complete story of these one-of-a-kind institutions.

\section{First Generation of Tool Libraries (Mid-1940s)}

The Second World War was responsible for depleting basic supplies on the U.S. home front including kitchen and yard tools. Raw materials that usually went into the production of these items were syphoned off to support the war abroad, leaving Americans to deal with the tool shortage. To fix this problem, local communities pooled their tools and freely borrowed from the public stockpile. Eventually these informal reserves found their way into libraries, where some found a permanent home. Michigan's Grosse Pointe Public Library was the first to welcome tools into its collection and is the only institution from the initial wave of tool libraries that is still in existence.

\section{Grosse Pointe Public Library}

When navigating the Grosse Pointe Library's website, one is immediately struck by the strangeness of its offerings. Unlike cookie-cutter libraries that lend publications, Grosse Pointe has more than just books on its menu. Screwdrivers, aerators, and even X-Acto sets make up the tools housed at the library since the mid-twentieth century. These items are part of the library's special collections and were initially provided by the Boys' Work Committee of Grosse Pointe Rotary Club in 1943 (Severs, 1943). In light of the tool shortage brought about by the Second World War, members of the Rotary Club made generous donations of kitchen and yard tools to the library. These donations were intended to be shared by the local community and "encourage manual dexterity in the younger generation" (Grosse Pointe Public Library, n.d.). Since then, Grosse Pointe residents have come to the library to not only borrow books but also check out tools. It is believed to be the first tool library in the U.S. and houses tools ranging in complexity from a stapler to a wallpaper seam roller. Using a library card, patrons can freely borrow an array of tools that are traditionally too expensive to purchase or too inconvenient to store.

Initially, the nascent collection numbered twenty-five items and was stored in a small case in the middle of the library's reading room. Though it was not much, the original items helped locals weather the lack of tools and allowed the library to step into a new community role. Several tools from the initial donation, including an antiquated hand drill, still belong to the collection and are available for patrons to borrow. With the continued help of the Rotary Club, Grosse Pointe Library's collection has grown to more than 150 tools and is being actively added to, based on patron suggestions. The library has even expanded its 
holdings to include high-quality bird binoculars and a telescope-both of which were donated by the Ken Etherly Foundation - as well as an outdoor projector and a cornhole toss. These acquisitions are not tools per se but are popularly circulated among residents for use at "family gatherings and neighborhood celebrations" (Moran, 2019, para. 13). No matter the item selected and borrowed from the collection, all come with a complementary pamphlet that describes how to use the object.

Since the collection's founding, the Rotary Club has stepped forward to serve as the main caretaker of the tools. They not only purchase and create labels for new equipment, but they are also in charge of cleaning and repairing tools when needed. Given all that they do, it is undeniable that the Rotary Club's sponsorship is the key ingredient to the collection's success. Without their physical assistance and financial backing, it is very possible that the first U.S. tool collection may never have taken shape.

\section{Second Generation of Tool Libraries (Mid-1970s to 2008)}

After Grosse Pointe started the tool library movement, there was momentum for other libraries to follow suit. But rather than bringing library after library into its fold, the movement came to a sudden halt and became confined to Grosse Pointe. Over the next thirty-three years, the small Michigan suburb would be the only place to have a tool collection on U.S. soil. It was not until the second wave of tool libraries surfaced in the mid-1970s that the movement finally gained traction and began to spread.

The long pause begs an obvious question: Why did new tool libraries take so long to come about? A number of hurdles are responsible for delaying their emergence, with one being the difficulty of operating collections manually.

Libraries, lacking the necessary technology to efficiently catalog tools, simply gave up on the idea of tool collections before even trying them out. Still, other factors dissuaded libraries from pursuing tool lending. The rise of consumer culture coupled with the availability of cheap products made overseas led to a diminished desire for durable, well-crafted tools (Llewellyn, 2019). Together, these elements made tool libraries infeasible for years. Only after patrons remembered the joy of working with high-quality tools did the second generation of tool libraries enter into the picture.

\section{ModCon Living Tool Library}

More than three decades after Grosse Pointe established the first tool-lending library, a second was founded in the nearby state of Ohio. In 1976, the city of Columbus eked out funds to construct a tool library meant to support local homeowners. So long as residents could prove themselves to be homeowners or tenants, the tools were at their free disposal. Housed in an unremarkable warehouse, the makeshift library began with a modest assortment of tools that later expanded to a collection of over 5,000. Hammers, drills, hoes, and tillers make up some of the items found there, but other, more archaic tools can also be discovered. Outdated nail pullers and bush removers lend the library an oldfarmer's-shed quality, but most of these tools represent the library's first purchases. Take, for example, the bush remover. For $\$ 230$ - a steep price for the 
newly developed library - the handmade device was purchased and integrated into the collection. Decades later, requests for the medieval-looking tool are still common, leaving librarians wishing they had purchased more (Weiker, 2015).

Even if patrons cannot get a hold of the popular bush remover, thousands of other tools are regularly available for checkout. With the swipe of a barcode, library members can borrow equipment for up to a week, free of charge. Some high-demand items, however, can only be leased for a day before they must be returned. These include ladders and lawn mowers, the second of which switches hands two to three times per day in the busy summer months (Weiker, 2015).

In 2009, management over the tool library was assumed by ModCon Living - a non-profit organization devoted to sustaining old homes in Franklin County. The takeover has breathed new life into the library, which now has more volunteers helping to catalog and repair its inventory. The tool library has also begun to create video demonstrations on how to repair common problems around the house using tools from the collection. The latest video shows audiences how to deal with leaky faucets (Williams, 2020). Whether in the form of tools or videos, the resources made available by the ModCon Living Tool Library have empowered Columbus homeowners to carry out DIY home repairs and renovation projects.

\section{Phinney Tool Library}

Since 1977 Seattle, Washington residents have been welcome to borrow what they need from the Phinney Tool Library without incurring the cost of a tool they may never use again (McGrath, 1992). With up to 3,000 items to choose from, patrons are guaranteed to find whatever tool they need for their next project. The tool bank consists of average hand and power tools like drills, staple guns, and wrenches as well as bike repair tools and cleaning supplies. Other items in the library's possession include apple pickers and cider presses, which fly off the shelves during the appropriate season.

The Phinney Tool Library was initially the work of a professor from the nearby University of Washington (McGrath, 1992). Students - wishing to clear out their dorms and offload their unused tools-approached the professor who turned their trash into community treasures. The library began as a small locker of basic tools but quickly swelled to hundreds of items. Growing to a size that was unmanageable for the professor, the tool library was passed off to the Phinney Neighborhood Association (PNA) (Castleman, 2019). Ever since, the PNA has been responsible for cataloging, maintaining, and fixing tools in the collection. When volunteers identify tools that are broken beyond repair, they tap local artists who recycle the damaged items and repurpose them as lamps or sculptures (Castleman, 2019). At the Phinney Tool Library, not much goes to waste.

\section{Third Generation of Tool Libraries (2008 to Present)}

Between the 1970s and 2000s, the number of tool libraries in the nation gradually increased from one to several dozen. A sudden uptick, however, came in 2008 when the Great Recession put millions of Americans out of work. Strapped for cash, the unemployed could no longer afford to purchase expensive tools to maintain their homes. Rather than buying and owning tools, Americans grew 
interested in sharing equipment. What came of this shift in attitude was an explosion of tool libraries. Within the next decade, the number of libraries offering tool-loaning services multiplied twofold as it made sense to more and more people to borrow cheaply (Urban Sustainability Directors Network, n.d.). The Sacramento Library of Things in California and Chicago Tool Library in Illinois represent just two of the many institutions that joined the ranks of the tool-lending movement. Due to their saturation in the library literature, this paper will not explore specific institutions linked to the third wave of tool libraries. It is enough to know that tool libraries are continuing to boom despite economic recovery, a sure sign that they are here to stay.

Cloud-based software has further facilitated the recent popularity of toollending libraries. New technologies like myTurn are allowing libraries to keep track of their inventory affordably while also improving the efficiency of cataloging. The advantages of myTurn are not restricted to librarians, however. Patrons, too, are reaping benefits from this platform as it enables them to easily rent tools online. The increased convenience has had a marked effect on tool libraries, helping to increase their circulation by a remarkable 100 to 10,000 percent (Llewellyn, 2019). Integrating such software has both eased the lending process and expanded patron access to tool collections. For these reasons, toollending libraries are faring better now than ever and only seeing their popularity climb.

So well liked are these libraries that they have recently crossed international borders and become established in Europe. One particular region where tool libraries have taken off and experienced wide public support is the United Kingdom. In 2015, Scotland's Edinburgh Tool Library was founded and became the first institution of its kind in the U.K. Local demand resulted in the library's growth to include sites like Leith and Portobello-both of which represent underserved areas in the Scottish capital (Edinburgh Tool Library, 2017). London soon followed suit and opened its own Library of Things in 2018. It is run exclusively by volunteers dedicated to making tool recycling a community norm and helping local organizations build tool-lending collections of their own (Library of Things, n.d.). With this much interest surrounding tool libraries, the movement is sure to spread to neighboring countries and possibly other continents. Luckily, libraries around the world have examples of thriving tool collections in the U.S. to follow.

\section{Conclusion}

For too long, the scholarly literature has been ignorant of important historical facts - namely, that the BTLL is not the first U.S. library to lend tools. It was one of the earliest and most conspicuous to appear but did not predate Grosse Pointe - a mid-sized library that has successfully loaned kitchen, garden, and home repair tools for more than seventy years. This institution, along with other early tool lenders, was unfairly eclipsed by the BTLL until now. The new historical timeline proposed in this paper sheds much-needed light on those that came before. By pushing the origin of tool libraries back to 1943, four decades have been added to the original narrative. The tool libraries that were born in those lost years deserve to be recognized and further studied if the complete story 
School of Information Student Research Journal, Vol. 11, Iss. 1 [2021], Art. 4

of these unique institutions is to be understood. 


\section{References}

Berkeley Public Library. (n.d.). Tool lending library: A brief history. https://www.berkeleypubliclibrary.org/locations/tool-lending-library/toollending-library-brief-history

Broner, A. (2017). Measure twice, cut once: A long-lasting tool lending library in Berkeley. In M. Robison \& L. Shedd (Eds.), Audio recorders to zucchini seeds: Building a library of things (pp. 29-42). Libraries Unlimited, an imprint of ABC-CLIO.

Castleman, A. (2019, May 30). Welcome to the library of things. Sierra Magazine. https://www.sierraclub.org/sierra/welcome-library-things

Dahlkild, N. (2011). The emergence and challenge of the modern library building: Ideal types, model libraries, and guidelines, from the Enlightenment to the experience economy. Library Trends, 60(1), 11-42. https://doi.org/10.1353/lib.2011.0027

Edinburgh Tool Library. (2017). About us. https://edinburghtoollibrary.org.uk/about/

Grosse Pointe Public Library. (n.d.). Special collections. https://grossepointelibrary.org/special-collections

Gunnels, C. B., \& Green, S. E. (2018). Models of service in an age of acceleration. In J. M. Matarazzo \& T. Pearlstein (Eds.), The Emerald handbook of modern information management (1st ed., pp. 289-314). Emerald Publishing Limited.

Hult, A., \& Bradley, K. (2017). Planning for sharing: Providing infrastructure for citizens to be makers and sharers. Planning Theory \& Practice, 18(4), 597-615. https://doi.org/10.1080/14649357.2017.1321776

Lending tools for the hands as well as the mind (2011, September-October). Natural Life Magazine, 29.

Library of Things. (n.d.). The why. https://www.libraryofthings.co.uk/why Llewellyn, T. (2019, April 29). The evolution of the tool library. Grassroots Economic Organizing. https://geo.coop/story/evolution-tool-library

Martell, C. (2008). The absent user: Physical use of academic library collections and services continues to decline 1995-2006. Journal of Academic Librarianship, 34(5), 400-407. https://doi.org/10.1016/j.acalib.2008.06.003

McGrath, S. (1992, May 31). Home repair made easier: Check out (or start) a tool library. The Seattle Times. https://archive.seattletimes.com/archive/?date=19920531\&slug=1494809

Moran, K. M. (2019, October 15). Borrow saws and more through library's 'cutting edge' tool collection. Grosse Pointe Times.

https://www.candgnews.com/news/borrow-saws-and-more-throughlibrarys-cutting-edge-tool-collection-115381

Moyer, J. E., \& Thiele, J. (2012). E-books and readers in public libraries: Literature review and case study. New Library World, 113(5/6), 262-269. https://doi.org/10.1108/03074801211226346 
Riley, S. (2014, August 18). New Florida university unveils bookless library. Library Journal. https://www.libraryjournal.com/?detailStory=newflorida-polytechnic-unveils-bookless-library

Scott, R. (2011). The role of public libraries in community building. Public Library Quarterly, 30(3) 191-227. https://doi.org/10.1080/01616846.2011.599283

Severs, F. H. (1943). Tool library for Grosse Pointe. Michigan Librarian, 9, 23.

Söderholm, J. (2018). Borrowing and lending tools: The materiality of x-lending libraries [Doctoral thesis, University of Borås]. Digitala Vetenskapliga Arkivet Portal. https://www.divaportal.org/smash/get/diva2:1192733/FULLTEXT01.pdf

Söderholm, J., \& Nolin, J. (2015). Collections redux: The public library as a place of community borrowing. The Library Quarterly, 85(3), 244-260. https://doi.org/10.1086/681608

Staff of the Worthington Library. (2010). Tracking trends in the future of Worthington Library. Public Library Quarterly, 29(3), 230-271. https://doi.org/10.1080/01616846.2010.502039

Svensson, P. (2018, February 01). Hammer drills instead of books - libraries have an identity problem. Dagens Nyheter. https://www.dn.se/ledare/signerat/per-svensson-slagborrar-istallet-forbocker-biblioteken-har-ett-identitetsproblem/

Urban Sustainability Directors Network. (n.d.). Tool lending libraries. https://sustainableconsumption.usdn.org/initiatives-list/tool-lending$\underline{\text { libraries }}$

Weiker, J. (2015, July 19). On the house: Library lends tools of all types, for all needs. The Columbus Dispatch. https://www.dispatch.com/article/20150717/LIFESTYLE/307179591

Williams, K. (2020). The first ever tool library was started in Columbus in 1976 and it's still a life-changing service today. Columbus Navigator. https://www.columbusnavigator.com/franklin-county-tool-library/

Weinstein, D. (2008). It came from Berkely: How Berkley changed the world. Gibbs Smith. 